\title{
Being Safety Smart: Social Issue Game for Child Protective Behaviour Training
}

\author{
Christian Martyn Jones \\ University of the Sunshine Coast \\ Maroochydore, Queensland, Australia \\ cmjones@usc.edu.au
}

Kay Pozzebon

kpozzebo@usc.edu.au

\begin{abstract}
Being Safety Smart is an online, social issue game designed to mitigate increasing child abduction rates in Australia. By teaching young children skills and strategies to help protect themselves, the game empowers children with the ability and confidence to act appropriately and decisively. This paper reports on the collaborative research and development of Being Safety Smart, bringing together global best practice in child protection and computer game design to create an educational resource targeted to children aged 6 to 8. The anti-abduction messages and strategies were developed in partnerships with Australian government departments of the Queensland Police Service, the Crime and Misconduct Commission, the Department of Communities (Child Safety Services) and Education Queensland. The gaming environment is aligned to age and gender specific learning capabilities of children and is based on eight key features associated with children's acquisition and retention of protective behaviour concepts and skills. Results of a successful evaluation of the program with schools are presented. Being Safety Smart received the 2009 Queensland Police Service gold award for excellence in crime prevention.and is being used in over 200 schools across Australia.
\end{abstract}

Social issues games, Serious gaming, Games-based learning, Animation, Storytelling, Child safety, Sexual abuse prevention, Anti-abduction, Social and psychological evaluation

\section{BACKGROUND}

In Australia, the rate of abduction increased from 2.5 to 3.8 victims per 100,000 population between 1995 and 2004 (the most recent statistical survey from the Australian Bureau of Statistics) [1]. Throughout this period the rate of kidnapping of persons aged 19 or less has been more than twice as high as of persons aged 20 and over. In 2004, of the 768 people who were abducted, 69 percent were female, while the rate for females aged 10-19 years was 17.5 per 100,000 .

Where victim/offender relationship was reported in 2003 , abduction by offenders previously not known to the victim was most common (62\%), followed by abduction by a non-family member known to the victim (18\%), and by a family member (12\%) [1]. Increasing abduction numbers led to the development of the 'stranger danger' strategies however stranger danger does not help prevent child abduction and abuse when the child is known to the perpetrator.

Furthermore, the most vulnerable age for abduction and abuse is between 7 and 13 years [2], and 84\% of sexually abused children are victimised before age 12 [3]. Therefore there is a need for a combined resource which can provide advice to young children to minimise the risk of abduction and provide practical strategies to escape situations that may arise.

The Being Safety Smart project originated in response to the increasing risk of child abduction in Queensland. Child abduction was brought to public attention with the disappearance of a 13yearold Australian boy, Daniel Morcombe, in 2003. The Morcombe case is one of the most extensively investigated crimes in Queensland's criminal history and the Morcombe family has offered a total reward of $\$ 1,000,000$ AUD.

Research has suggested that children in regional and remote areas may be at greater risk of abuse than children in other areas [4]. In response, the project developed an internet delivered game that enables children in regional and remote areas to access the safety awareness message.

\section{BEING SAFETY SMART AIMS}

The aims of the project were to research and compile anti-abduction strategies for children aged 6 to 8; develop a computer game through which children can learn safety awareness strategies in the safe and controlled environment of the classroom; evaluate child learning gains in personal safety associated with participation with the game; and monitor and measure the effect of the messages on child behaviours.

\subsection{Design of Key Messages and Game}

The Being Safety Smart project is based on global best practice messages from other programs, 
including KlassKids Foundations, Yello Dyno, Kids Help Line, Safer Child Inc, Family Education, FBI Kids and Stay Safe. Additionally, Being Safety Smart is built on a review of child-focused sexual abuse prevention programs which compiled 8 key features associated with children's acquisition and retention of prevention concepts and skills [5]:

1) Active participation. Programs that encourage active participation of children (eg through roleplay) are more effective than those that use either passive methods (eg traditional teaching, classroom discussions) or no participation (eg videos, written materials, self study).

2) Explicit training. Allowing children to rehearse appropriate behaviours is associated with greater gains in skills and knowledge over non-behaviour techniques (eg lectures, videos, puppet shows).

3) Group training. Training in a group can be better than individual training as the group setting removes the isolation of individual programs which can make children more fearful.

4) Standardised materials. Programs are more effective if they involve standardised materials and are taught by trained instructors.

5) Integrated into school curriculum. Programs are more effective if they are integrated into the school curriculum with designated times for delivery and support.

6) Longer programs. Longer programs involving repeated presentations and followed by summaries to reinforce training are more effective than shorter programs.

7) Parental involvement. Children benefit more from prevention training if their parents are also included in the program.

8) Teacher education. Programs that include teacher education are more effective in helping children to retain their prevention training.

\section{EFFECTIVE LEARNING}

The Being Safety Smart game adopts these eight key features of successful abuse prevention programs.

\subsection{Active Participation}

The game is designed to allow children to roleplay skills and scenarios in the safe and secure environment of the classroom. Children can experiment to find the appropriate response in situations, minimising fear or anxiety (see Figure 1). If the child selects an incorrect response to a scenario they are not shown a potential negative consequence of that action, but instead are presented with the correct action response to reinforce their learning. This active participation through role-play affords greater knowledge gains for children than passive learning methods such as teacher led discussions, or non-participatory methods such as watching videos of abduction scenarios and re-enactments [6-8].

The stories and scenarios in Being Safety Smart are based on real-life abduction attempts compiled by Queensland Police Service (QPS) and designed to be realistic and relevant to the child.

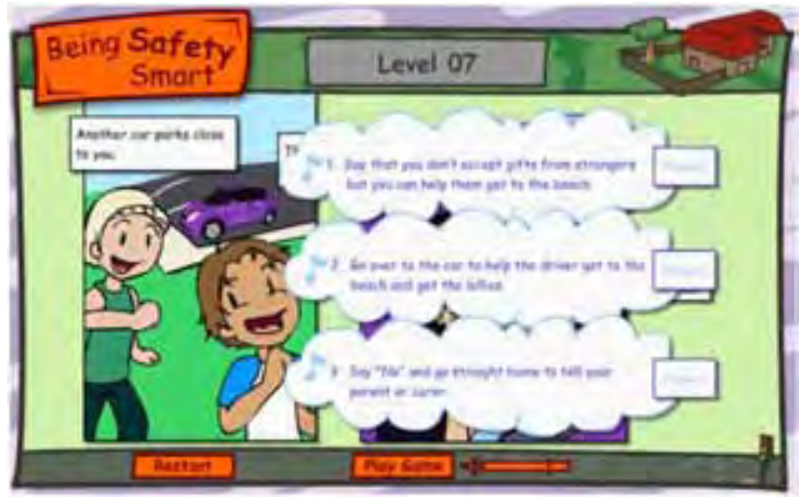

Figure 1. Example 'active participation' screenshot where child has choice of response to situation

\subsection{Explicit Training}

Child safety programs are often designed primarily to meet the protection needs of girls, and may not provide adequate prevention training for boys [9]. Gender differences need to be incorporated into prevention training, as boys are less likely to believe that they can be abducted, so they often engage in more risk-taking behaviour. Compared with girls, boys have poorer problem solving skills when they are presented with dilemmas. Many boys favour 'superhero' responses, or more confrontational, less planned strategies, which are often focused on physical aggression [5, 10-11]. The Being Safety Smart game contains scenarios and activities relevant and appealing to both girls and boys, and are voiced by girls and boys.

Through collaboration with schools, teachers, parents and children, the project iteratively developed the message content, language, presentation and interaction to be engaging, relevant and rewarding for both boys and girls. For example, a scenario involving playing football at the park (which could be considered to be gender specific) was changed to flying a kite. 


\subsection{Group Training}

Being Safety Smart is designed to be delivered in a teacher supported group learning setting. However the resource is also designed to support the child to participate individually and without adult guidance. Education Queensland recommends the use of interactive smart boards for computer-based teaching in the classroom. The multimedia resource has been designed to allow teachers and children to interact with stories and games via the smart board and in a group setting.

\subsection{Standardised Materials}

The key child safety messages are based on existing programs and the experience of QPS, the Crime and Misconduct Commission (CMC), the Department of Communities -Child Safety Services (DCS) and Education Queensland (EQ). The team developed training materials to support the online game in collaboration with teachers and behaviour/ guidance officers from EQ.

\subsection{Integrated into School Curriculum}

The team worked in collaboration with school teachers to align the resource to school curricula for ages 6 to 8 . The program is specifically linked to the EQ year three Essential Learnings of Health and Physical Education, Studies of Society and Environment (SOSE) and Information and Communication Technologies (ICT).

\subsection{Longer Programs}

The program contains 8 levels and is designed to be delivered over 8 weeks. Each level includes i) repeated presentation of the key messages; ii) role-play to test skills and strategies in a safe and secure environment; iii) game-play to reiterate key messages; iv) and summaries which can be printed as award certificates.

\subsection{Parental Involvement}

Parents are involved in the program through i) information handouts to discuss with their child (prior to a level); ii) additional parent information sheets made available when the child completes a level which can be printed and taken home; iii) and parental access to the online resource, so parents can learn the skills and strategies themselves and discuss them with their child.

\subsection{Teacher Education}

Teachers have been involved in the research, design, implementation, and evaluation of the project. Teachers have suggested how they can embed the program into classroom activities with worksheets and exercises, and that teacher created activities and support materials can be shared with other teachers to support training.

\section{DESIGN OF THE GAME}

Being Safety Smart is a Flash game with an encrypted SQL database recording secure login access for schools and users. The game was developed with children and makes use of graphic conventions familiar to children such as supersaturated colours, comic strip panels, and Japanese Anime style characters.

Table 1. Key safety messages and their location in the virtual game environment

\begin{tabular}{|l|l|l|}
\hline Level & Key Message & Location \\
\hline 1 & Ask parents first & My house \\
\hline 2 & Stick with your buddy & Friends House \\
\hline 3 & Watch where you are going & School \\
\hline 4 & Trusted friends & Backyard \\
\hline 5 & Finding help if you're lost & Shopping Centre \\
\hline 6 & Know and use your codeword & Sports Club House \\
\hline 7 & Being safe when out and about & Park \\
\hline 8 & It's okay to shout and tell & Playground \\
\hline
\end{tabular}

The game is staged, allowing more complex messages to be presented only after the completion of the core messages. The key safety awareness messages are presented as eight distinct levels, where each level is located within the child's virtual world (see Table 1). The child selects levels from an interactive map of their virtual world (see Figure 2). Locations become available on successful completion of a previous level such that the child progresses sequentially through the key messages, building on prior learning with more complex skills and strategies.

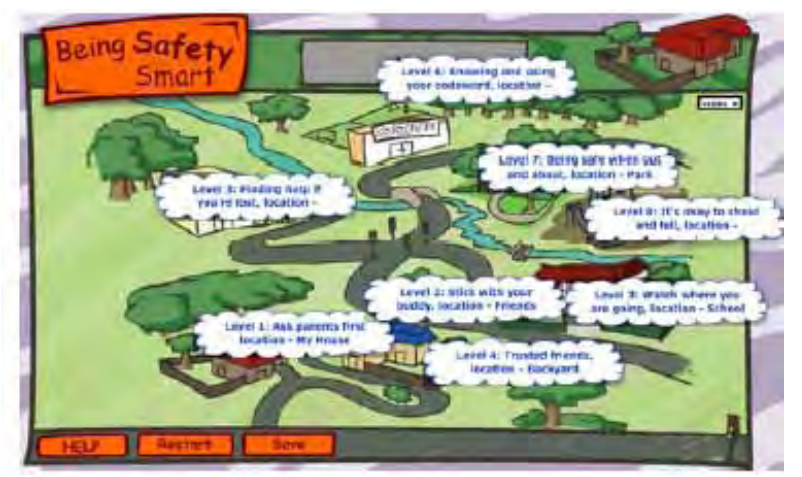

Figure 2. Map view (with all mouse roll over messages)

On first entering the game environment, and on completion of each game level, the child is placed 
in their personal virtual lounge room (see Figure 3). The virtual lounge room combines top-level navigation with progress indication, and was chosen as a "home" metaphor because it is a familiar and safe environment for children. From here the child can access levels (by selecting the TV displaying the map), create and edit their avatar (by selecting the photo frame), and view and print awards and additional information sheets (displayed on the wall and bookshelf).

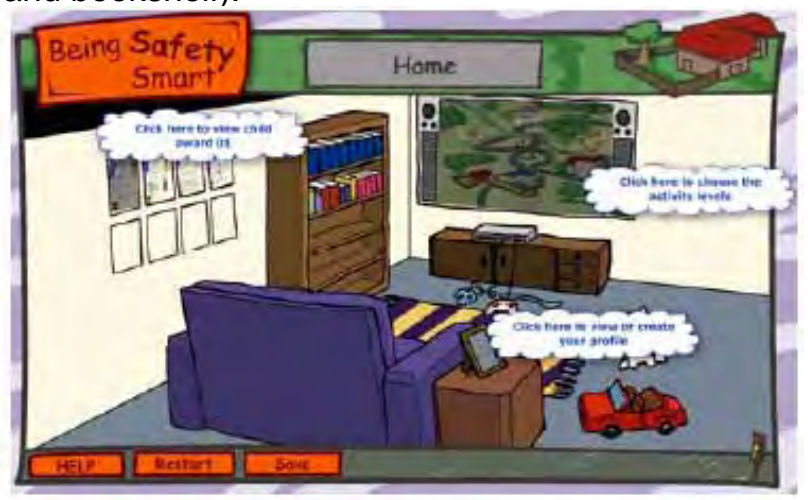

Figure 3. Lounge room 'home' screen allowing child to select levels, create their avatar profile, and view certificates and parent information

On first login the child creates an avatar to represent themselves in the game (see Figure 4). This avatar and the child's name are displayed throughout the environment in the stories and scenarios, the interactive games, and on the certificates and awards. The personalised character has been found to offer greater engagement of the child with the content.

Each level comprises:

1) An instructional section

2) Activity/game sections

3) Summary of key points

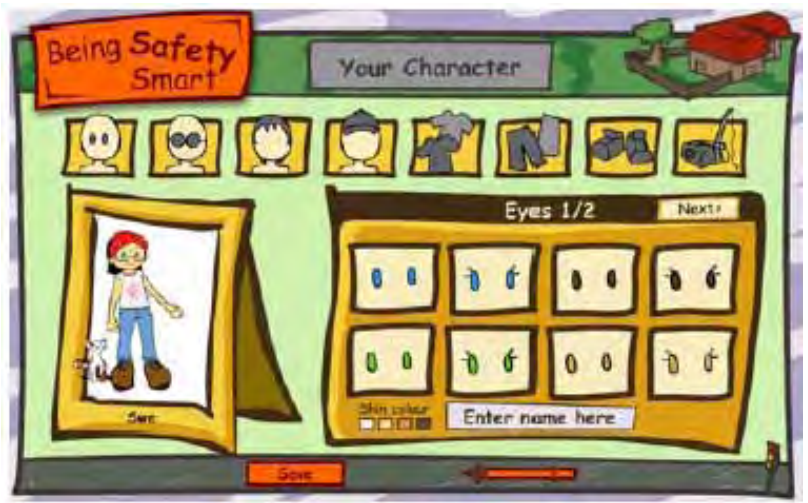

Figure 4. Avatar creator to represent child in game and on personalised awards

\subsection{Instructional Section}

The instructional section presents the key child safety awareness messages for the level using comic-style panels, windows and fonts, together with dynamic animations of stories and scenarios (see Figure 5).
All textual information is also presented as an audio track spoken by children of the same age to provide a sense of peer support.

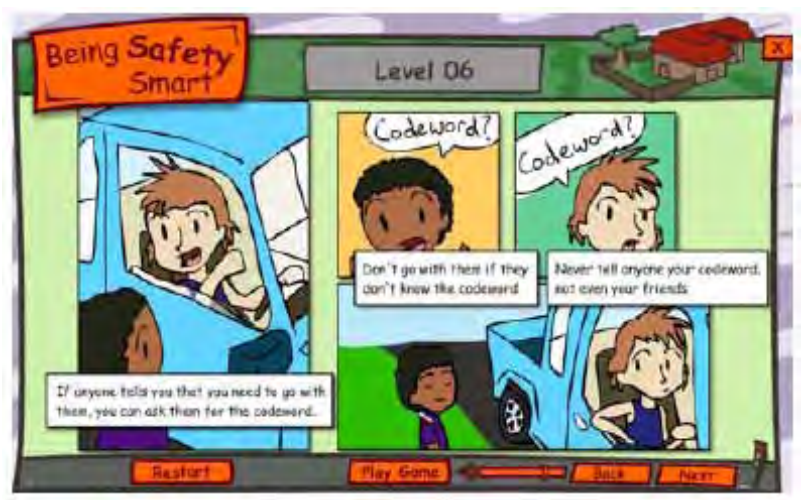

Figure 5. Example instruction section of game showing key codeword message

\subsection{Activity/Game Section}

The activity/game section reiterates the messages presented in the instructional section and tests the child's understanding through interactive role-play and games. There are three main types of activity i) choice from three options as to what should you do now?' (see Figure 6); ii) selection of correct items from display of multiple items (see Figure 7); iii) and interactive games (see Figure 8). The child is given additional information for each incorrect and correct selection to reinforce the appropriate behaviour.

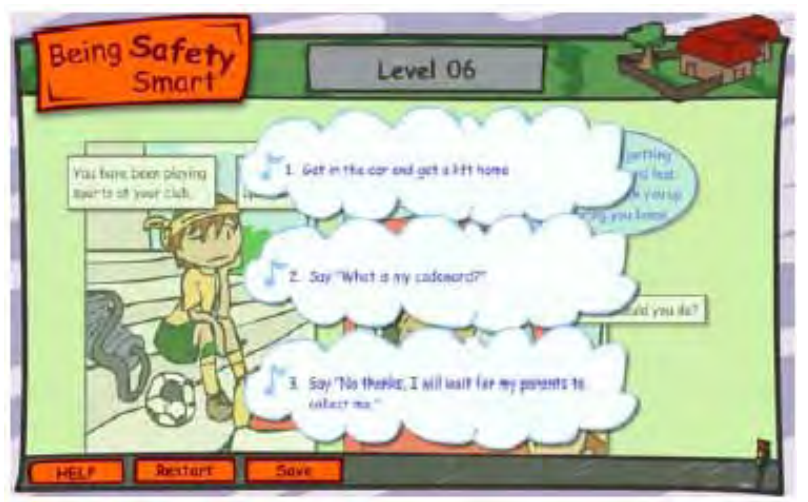

Figure 6. Example 'What should you do now?' activity

There are interactive minigames throughout the 8 levels. These include drag and drop recognition of a Police Officer and Police car (see Figure 9), photo fit game to create people (see Figure 10); maze games to navigate from home to school along safe routes (see Figure 8); and Trusted Adults that can lend a hand (see Figure 11). 


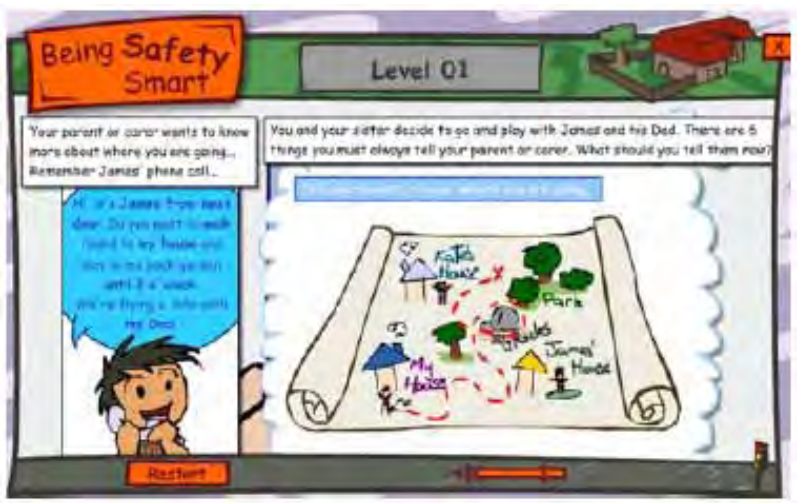

Figure 7. Example of choice from multiple items activity

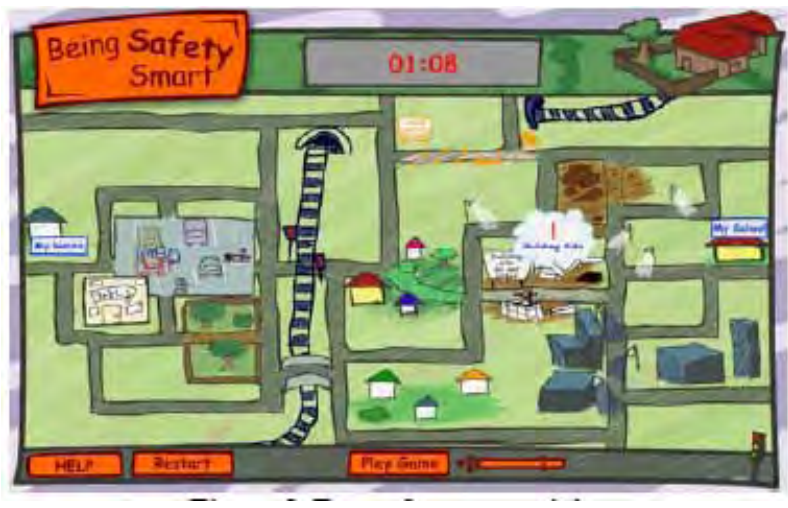

Figure 8. Example game activity

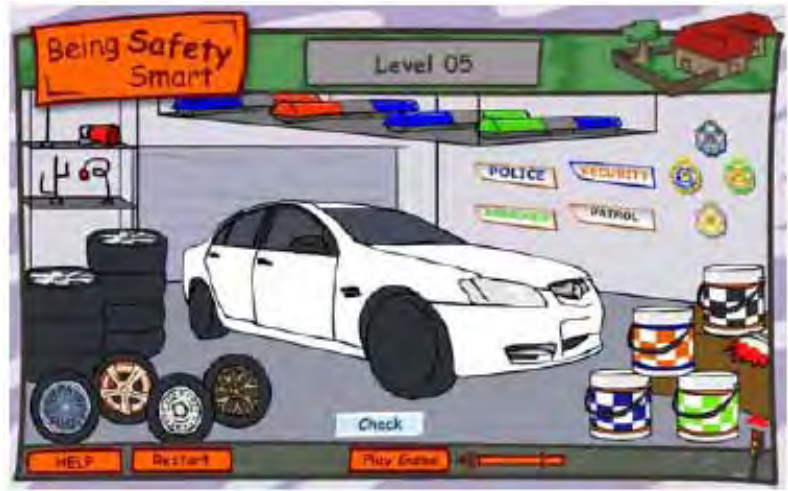

Figure 9. Example drag and drop Police Car game

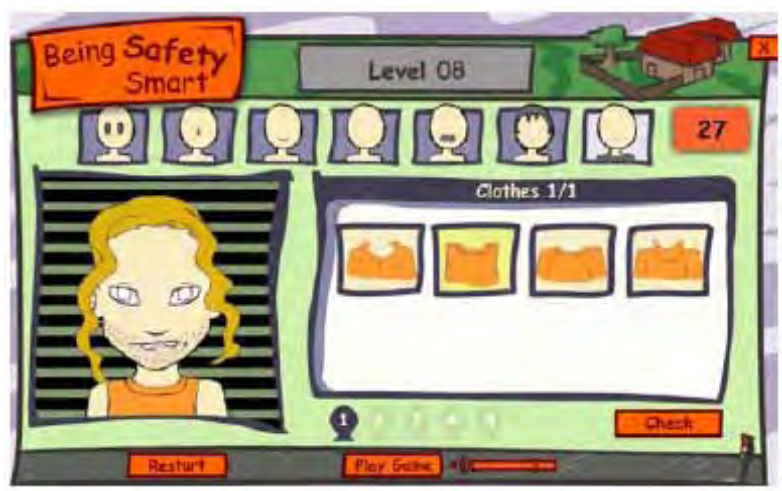

Figure 10. Example photo fit game to recognise faces

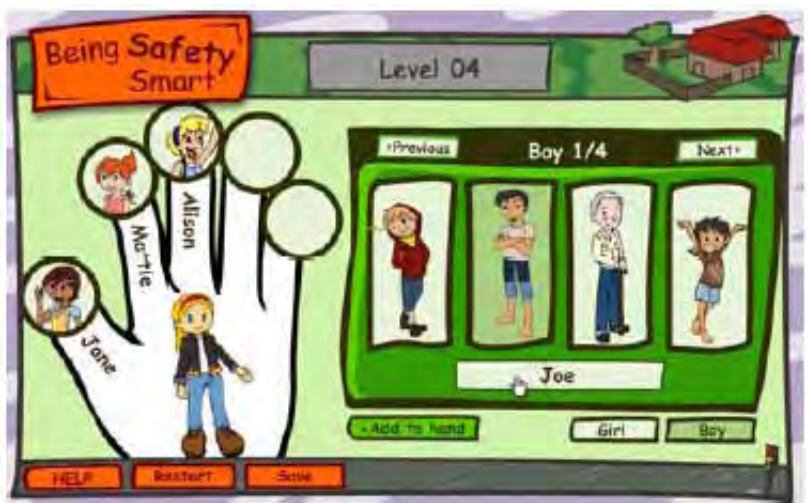

Figure 11. Example interactive game - My Trusted Adults

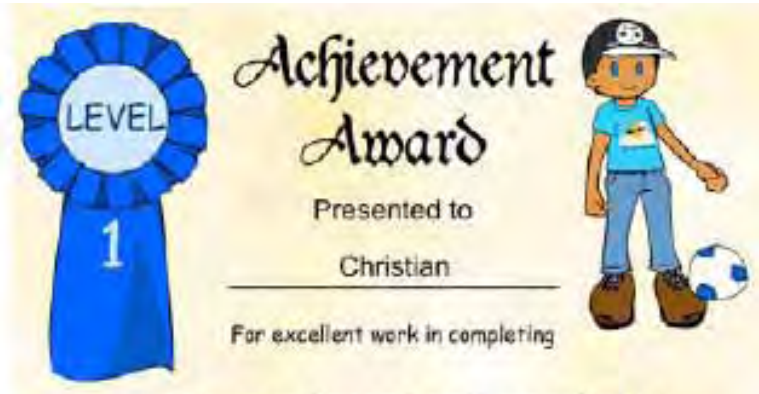

"Ask your Parent or Carer first"

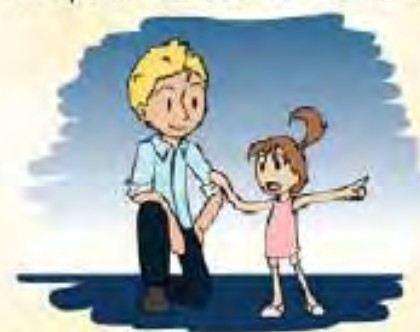

Always ask your porents or caver before you go anywhere with anyone Six things to tell your parents or carer.

- Where you ore going Help you con get when you reo there

- How you will get there When you will get back

- Who will be going with you - Get back on time or phone

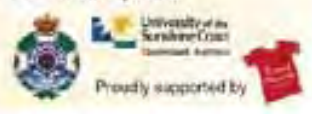

Figure 12. Example child award certificate for level 6 (which can be printed by child and signed)

\subsection{Summary Section}

On completion of the instructional section and interactive activities, the child is presented with a summary page for the level with images and animations to reiterate the key safety awareness messages. The child is then returned to the virtual lounge room where a personalised award certificate is displayed on the wall. Additionally, an accompanying information sheet for parents and carers is available on the bookcase. The child award certificate is image based with few words but includes the child's name and virtual character (see Figure 12). The parent and carer sheet explains in more detail the messages of the level (see Figure 13). 


\section{Lever 1}

Ask parent or carer first

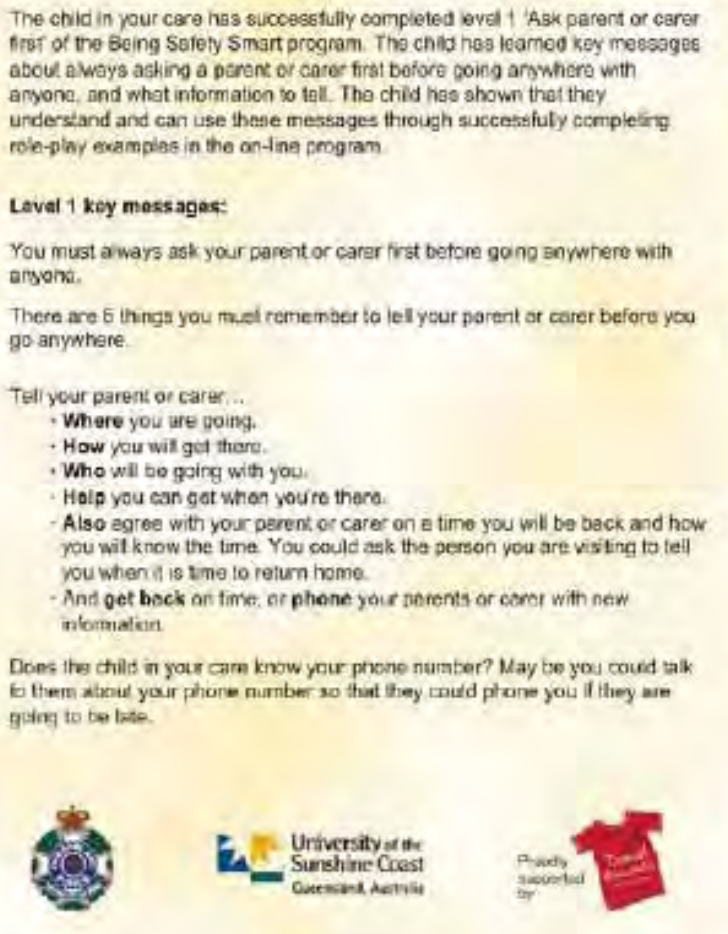

Figure 13. Parent and carer information sheet for level

The bottom left hand side of the child award certificate is left blank so that schools can add their stamp and/ or have the principal or teacher sign (see Figure 12). Also if the school has an 'Adopta-Cop' they can sign the child certificate. Signing certificates helps to demonstrate the importance of the messages for the child.

\section{PROJECT EVALUATION}

Child-focused safety awareness programs exist in different media and formats. However very few have been rigorously evaluated and can evidence positive gains in child learning and behavioural support. Only $2.6 \%$ of sexual abuse prevention programs $[5,12]$ included a comprehensive evaluation that compared the prevention knowledge of participant children with their counterparts in a control group that did not receive the program.

Being Safety Smart has been evaluated in schools using counterpart control groups. The evaluation aimed to assess the effectiveness of the project in providing safety awareness knowledge and skills to children and the retention of knowledge and skills. In each school the children were divided into two groups: experimental (participated with the safety awareness multimedia game environment) and control (no access to the safety awareness materials). After evaluation was complete, the control group also completed the game, thereby minimising any chance that they are less well prepared for potential abductions. In practice the experimental and control groups were formed from classroom groups. Parents were required to consent to their child participating in either of the experimental and control groups, and teachers were briefed to minimise any possibilities for the child safety awareness skills and strategies to be discussed between children in the experimental and control groups.

A single group outcome design was used to evaluate the program from the perspective of parents and carers, teachers and children. Data was collected before and after the program. Questionnaire measurements included an adaptation of the Children's Safety Knowledge and Skills Questionnaire [13] to measure the child's preand post-understanding of abduction situations and the Battle Culture-Free Self-Esteem Inventory [14] to measure child self-esteem and confidence. In addition to these adaptations, questionnaires were developed for the project, including a Parent's (and Teacher's) Knowledge and Attitudes questionnaire to evaluate changes in parents/teachers knowledge, and a Parent's (and Teacher's) Project Evaluation questionnaire to evaluate the impact of the project on child self-protection skills and self-confidence.

Parents completed a pre-participation questionnaire to assess their knowledge of anti-abduction and sexual abuse prevention issues, together with general knowledge of abduction problems. The participating child completed a pre-involvement questionnaire to evaluate their safety knowledge and skills.

The children completed one level each week for 8 weeks under the guidance and support of the teacher. On completion of the program, the child and parent completed post-participation questionnaires to determine any changes in attitude and knowledge. Learning skills to combat abduction carries a risk that the child may become confused and react inappropriately in normal and safe situations. However the materials will be learned through play and activities on a computer based resource, allowing the child to experiment (in the third person) within a safe and teacher supported environment. In all cases, the research team, teachers and parents monitored child behaviour for inappropriate use of learned strategies, anxiousness, distress, and confusion, and support the child with additional care and teaching. All teachers and Education Queensland behaviour guidance officers were given adequate training to support the in-class activities. Additionally, procedures were put in place to support any cases of child sexual abuse disclosed to the researcher. Working closely with teachers and the QPS, CMC and DCS team, any disclosure would be forwarded to the appropriate authorities. 


\section{EVALUATION RESULTS}

In this paper we present the analysis of the protective behaviours knowledge gains for children participating in the Being Safety Smart program. The following results are based on the Children's Knowledge Questionnaire, which consists of 35 statements (see Figure 14). For each statement, the child was required to respond either $T$ for true, $F$ for false, and D for don't know. Scores could range from 0 to 35 . Children completed the same Children's Knowledge Questionnaire twice, once before the start of the program, and then again after the program. However, the children in the control group did not participate in the program.

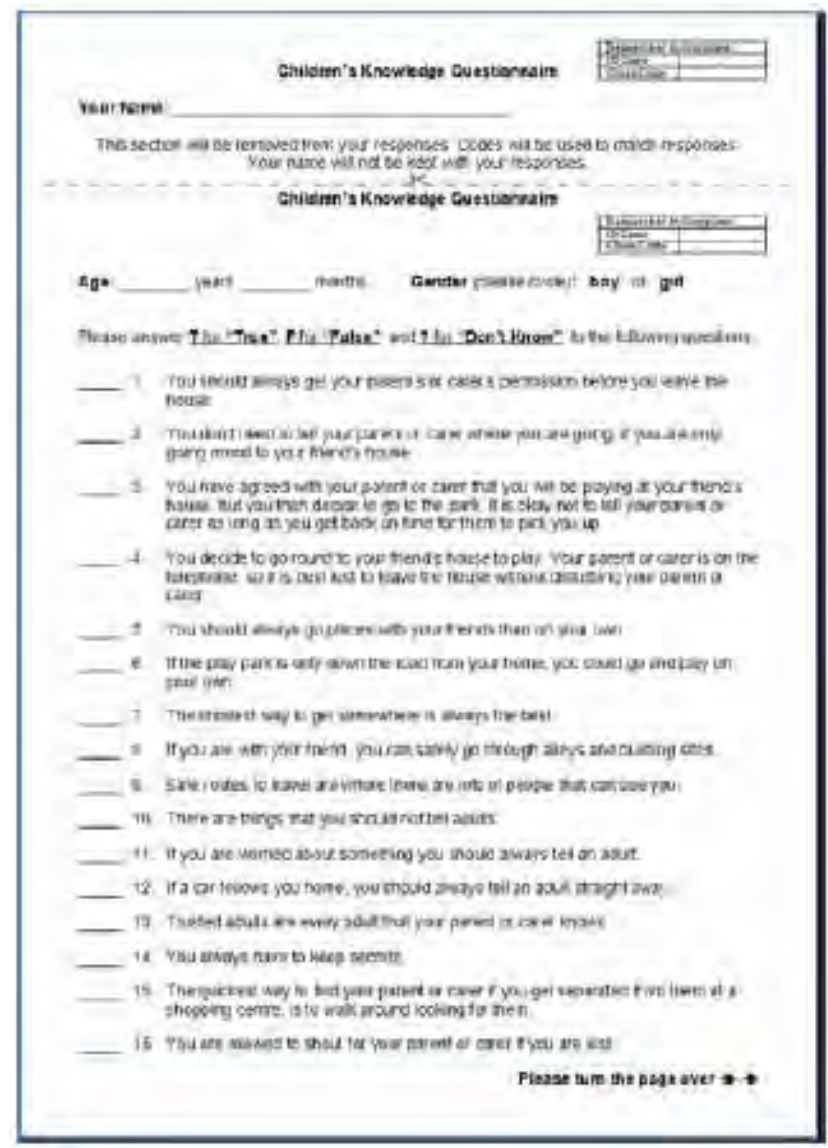

Figure 14. Children's safety awareness knowledge questionnaire

Prior to the commencement of the program, there was no significant difference in children's safety knowledge between the control and experimental groups, $t(68)=.587, p>.05$. Prior to running the program, both groups had approximately the same average score of around 23 out of 35 statements correct, suggesting that both groups were fairly equal in their knowledge of personal safety (see Table 2).
Table 2. Children safety awareness knowledge results before commencement of the program (group statistics)

\begin{tabular}{|l|r|r|r|}
\hline & \multicolumn{1}{|c|}{ N } & \multicolumn{1}{c|}{ Mean } & Std. Deviation \\
\hline Study Condition & 34 & 23.74 & 2.767 \\
Experimental Group & 36 & 23.14 & 5.394 \\
\hline
\end{tabular}

After the program, there was a significant difference in children's safety knowledge between the control and experimental groups, $t(74)=8.387, p=<.001$. After the program, the children who were involved in the program (i.e., the experimental group) had a significantly greater score (mean of 31 out of 35 safety statements correct compared to 24 out of 35 for the control group) (see Table 3). This suggests that the children who participated in the child safety awareness program had greater personal safety knowledge at the end, than those children who did not use the program.

Table 3. Children safety awareness knowledge results after completion of the program (group statistics). Note

the control group did not participate in the program

\begin{tabular}{|l|r|r|r|}
\hline Study Condition & \multicolumn{1}{|c|}{ N } & \multicolumn{1}{|c|}{ Mean } & Std. Deviation \\
\hline Control Group & 37 & 24.19 & 3.673 \\
Experimental Group & 39 & 31.49 & 3.913 \\
\hline
\end{tabular}

Comparing baseline and post program children's safety knowledge for the experimental groups only, a significant difference was found, $\mathrm{t}(32)=$ $10.502, p<.001$. This data compared each child's before program and after program personal safety knowledge. Results indicated that the children's personal safety knowledge did significantly improve, after being involved in the program (see Table 4).

Table 4. Children safety awareness knowledge before and after participating in the program (experimental group only - paired samples statistics)

\begin{tabular}{|l|r|r|r|}
\hline Study Condition & N & Mean & Std. Deviation \\
\hline $\begin{array}{l}\text { Baseline (Pre) - } \\
\begin{array}{l}\text { Children's Knowledge } \\
\text { Post - Children's } \\
\text { Knowledge }\end{array}\end{array}$ & 33 & 23.24 & 5.523 \\
\hline
\end{tabular}

Comparing baseline and post program children's safety knowledge for the control groups only, no significant difference was found, $t(39)=.1 .081, p$ $>.05$. This result indicates that the children's personal safety knowledge did not change over the course of the time of the program (see Table 5). 
Table 5. Children safety awareness knowledge before and after the program (control group only - paired samples statistics)

\begin{tabular}{|l|r|r|r|}
\hline Study Condition & N & Mean & Std. Deviation \\
\hline $\begin{array}{l}\text { Baseline (Pre) - } \\
\text { Children's Knowledge } \\
\begin{array}{l}\text { Post - Children's } \\
\text { Knowledge }\end{array}\end{array}$ & 30 & 24.07 & 2.449 \\
\hline
\end{tabular}

\subsection{Preliminary item analysis}

Prior to the commencement of the child safety awareness program, some items on the children's safety knowledge questionnaire were noted to have a large proportion of incorrect answers. After the completion of the program, the children in the experimental groups performed significantly better (see Table 6).

In Table 6, cells corresponding to the correct responses are shaded. The percentage of responses prior to the start of the program is provided first in the cell and the percentage of responses after the program is provided in parentheses. Note that the control group children did not experience the game. For example for the first item: 'Trusted adults are every adult that your parents or carer know', the correct answer is false. Prior to the program, only $30 \%$ of the children in the experimental group got this item correct. However, after participating in the program, $74 \%$ of children in the experimental group correctly answered this item. The baseline measures of the control group indicate that $24 \%$ of children got this item correct. Results indicate that after the program (noting that this group of children did not participate in the program), only $32 \%$ of children answered this item correctly.

The results show many more children understand correct safety strategies after completing the program compared to before using the program. The same significant increase in understanding of safety strategies is not observable with the control group. Also, for a number of the items listed below, it can be seen for the control group that the percentage of incorrect responses is greater than the percentage of correct responses.

\subsection{Feedback From Participants}

Results from the schools evaluation informed the iterative development of the project. The collaborative team including QPS, CMC, DCS, and Education Queensland behaviour officers responded to feedback from teachers, parents and children who participation in the program. For example, it was found that the 'maze game' was too difficult to control, and the penalties for taking an unsafe route was frustrating for the target child age group. The game was redesigned and tested to provide immediate and time limited penalties and to provide simple, keyboard arrow control key game play.

\section{CONCLUSIONS}

There is a growing need in Australia to educate young children with the skills and strategies to keep themselves safe from abduction. Being Safety Smart is an online, social issue game designed to mitigate increasing abduction rates in Australia by helping children to protect themselves and empowering children with the ability and confidence to act appropriately and decisively. The project is a collaboration between the University of the Sunshine Coast, Queensland Police Service, the Crime and Misconduct Commission, the Department of Communities - Child Safety Services and Education Queensland, and has been successfully trialled and evaluated in schools. The project uses academic and practitioner international best practice in child protection to develop safety messages for children. Relevant and realistic abduction scenarios are presented based on Modus Operandi from Queensland Police Service, which children can roleplay and learn protective behaviours in a safe and secure computer game. The program was launched in February 2009 and is being used by over 200 schools across Australia. Being Safety Smart received the 2009 Queensland Police Service Gold Award.

\section{ACKNOWLEDGEMENT}

The University of the Sunshine Coast gratefully acknowledges the support of Queensland Police Service, the Crime and Misconduct Commission, the Department of Communities - Child Safety Services and Education Queensland. 


\begin{tabular}{|c|c|c|c|c|c|c|}
\hline \multirow[t]{3}{*}{ Item } & \multicolumn{3}{|c|}{ Experimental Group } & \multicolumn{3}{|c|}{ Control Group } \\
\hline & $\mathrm{D}$ & $\mathrm{F}$ & $\mathrm{T}$ & D & $\mathrm{F}$ & $\mathrm{T}$ \\
\hline & \multicolumn{3}{|c|}{ baseline $f$ (post $f$ ) } & \multicolumn{3}{|c|}{ baseline $f($ post $f)$} \\
\hline $\begin{array}{l}\text { Trusted adults are every adult that your parents or } \\
\text { carer know (False) }\end{array}$ & $\begin{array}{l}24 \% \\
(12 \%)\end{array}$ & $\begin{array}{l}30 \% \\
(74 \%)\end{array}$ & $\begin{array}{c}46 \% \\
(14 \%)\end{array}$ & $\begin{array}{c}5 \% \\
(24 \%)\end{array}$ & $\begin{array}{l}24 \% \\
(32 \%)\end{array}$ & $\begin{array}{c}71 \% \\
(44 \%)\end{array}$ \\
\hline $\begin{array}{l}\text { You should not go anywhere with anyone even if } \\
\text { they say that they will help you find your parent }(\mathrm{T})\end{array}$ & $\begin{array}{l}10 \% \\
(7 \%)\end{array}$ & $\begin{array}{c}44 \% \\
(17 \%)\end{array}$ & $\begin{array}{l}46 \% \\
(76 \%)\end{array}$ & $\begin{array}{l}3 \% \\
(7 \%)\end{array}$ & $\begin{array}{l}64 \% \\
(57 \%)\end{array}$ & $\begin{array}{l}33 \% \\
(36 \%)\end{array}$ \\
\hline $\begin{array}{l}\text { If you are lost, the best person to ask for help is } \\
\text { from a mum with other kids (True) }\end{array}$ & $\begin{array}{l}22 \% \\
(2 \%)\end{array}$ & $\begin{array}{l}54 \% \\
(0 \%)\end{array}$ & $\begin{array}{l}24 \% \\
(98 \%)\end{array}$ & $\begin{array}{l}8 \% \\
(2 \%)\end{array}$ & $\begin{array}{l}38 \% \\
(53 \%)\end{array}$ & $\begin{array}{l}54 \% \\
(45 \%)\end{array}$ \\
\hline You can get help from anyone in a uniform (False) & $\begin{array}{c}24 \% \\
(10 \%)\end{array}$ & $\begin{array}{l}37 \% \\
(88 \%)\end{array}$ & $\begin{array}{l}39 \% \\
(2 \%)\end{array}$ & $\begin{array}{l}0 \% \\
(2 \%)\end{array}$ & $\begin{array}{c}39 \% \\
(48 \%)\end{array}$ & $\begin{array}{l}61 \% \\
(50 \%)\end{array}$ \\
\hline Using a codeword can keep you safe (True) & $\begin{array}{l}41 \% \\
(2.5 \%)\end{array}$ & $\begin{array}{l}15 \% \\
(2.5 \%)\end{array}$ & $\begin{array}{l}44 \% \\
(95 \%)\end{array}$ & $\begin{array}{c}29 \% \\
(17 \%)\end{array}$ & $\begin{array}{l}21 \% \\
(36 \%)\end{array}$ & $\begin{array}{c}50 \% \\
(47 \%)\end{array}$ \\
\hline $\begin{array}{l}\text { If someone says they need to give you a lift home, } \\
\text { only go with them if they know your codeword (T) }\end{array}$ & $\begin{array}{l}20 \% \\
(10 \%)\end{array}$ & $\begin{array}{c}41 \% \\
(39 \%)\end{array}$ & $\begin{array}{l}39 \% \\
(51 \%)\end{array}$ & $\begin{array}{c}18 \% \\
(14 \%)\end{array}$ & $\begin{array}{l}64 \% \\
(62 \%)\end{array}$ & $\begin{array}{l}18 \% \\
(24 \%)\end{array}$ \\
\hline $\begin{array}{l}\text { If someone you don't know has something that } \\
\text { belongs to you, and they try to give it to you, it is } \\
\text { okay to take it (False) }\end{array}$ & $\begin{array}{l}32 \% \\
(9 \%)\end{array}$ & $\begin{array}{l}44 \% \\
(86 \%)\end{array}$ & $\begin{array}{l}24 \% \\
(5 \%)\end{array}$ & $\begin{array}{l}13 \% \\
(2 \%)\end{array}$ & $\begin{array}{l}43.5 \% \\
(50 \%)\end{array}$ & $\begin{array}{l}43.5 \% \\
(48 \%)\end{array}$ \\
\hline $\begin{array}{l}\text { It is not what someone looks like that matters, but } \\
\text { what they ask you to do (True) }\end{array}$ & $\begin{array}{c}25 \% \\
(12 \%)\end{array}$ & $\begin{array}{c}29 \% \\
(12 \%)\end{array}$ & $\begin{array}{c}46 \% \\
(76 \%)\end{array}$ & $\begin{array}{c}23 \% \\
(36 \%)\end{array}$ & $\begin{array}{c}49 \% \\
(24 \%)\end{array}$ & $\begin{array}{c}28 \% \\
(40 \%)\end{array}$ \\
\hline $\begin{array}{l}\text { If an adult says "Don't go", you should stay with } \\
\text { them (False) }\end{array}$ & $\begin{array}{l}19 \% \\
(7 \%)\end{array}$ & $\begin{array}{l}54 \% \\
(88 \%)\end{array}$ & $\begin{array}{l}27 \% \\
(5 \%)\end{array}$ & $\begin{array}{c}31 \% \\
(15 \%)\end{array}$ & $\begin{array}{l}33 \% \\
(51 \%)\end{array}$ & $\begin{array}{c}36 \% \\
(34 \%)\end{array}$ \\
\hline
\end{tabular}

Table 6. Experimental and control group child knowledge, question by question data (selected questions). First \%age is prior to start of program, (\%age) is after the program. note: $D=$ don't know, $F=$ false, $T=$ true.

\section{REFERENCES}

[1] Australian Institute of Criminology. 2005. Crime facts info No. 103: Kidnapping and abduction, (2 August 2005) DOI=http://www.aic.gov.au/ publications/cfi/cfi103.pdf

[2] Finkelhor, D. 1994. Current information on the scope and nature of child sexual abuse. The Future of Children: Sexual Abuse of Children. 4, 2, 31-53.

[3] Ernest E.A. 1991. President of the National Centre for Missing and Exploited Children.

[4] Neame, A. and Heenan, M. 2004. Responding to sexual assault in rural communities, The Australian Institute of Family Studies, Canberra.

[5] Sanderson, J. 2004. Child-focused prevention of child sexual abuse programs, CMC, Australia.

[6] Davis, M.K. and Gidycz, C.A. 2000. Child sexual abuse prevention programs: a meta-analysis, Journal of Clinical Child Psychology, 29, 257-65.

[7] Finkelhor, D. and Strapko, N. 1992. Sexual abuse prevention education, in DJ Willis, EW Holden \& M Rosenberg (eds), Prevention of child maltreatment: developmental and ecological perspectives, John Wiley \& Sons, New York.

[8] Rispens, J, Aleman, A, and Goudena, P.P. 1997. Prevention of child sexual abuse victimization: a meta-analysis of school programs, Child Abuse and Neglect, 21, 975-87. [9] Bagley, C., Thurston, W.E. \& Tutty, L.M. 1996. Understanding and preventing child sexual abuse, vol. 1, Children: Assessment, social work, and clinical issues, and prevention education, Ashgate Publishing Ltd, England.

[10] Asdigian, N. and Finkelhor, D. 1995. What works for children in resisting assaults?, Journal of Interpersonal Violence, 10, 4, 402-18.

[11] Grober, J.S. and Bogat, G.A. 1994. Social problem solving in unsafe situations: implications for sexual abuse education programmes, American Journal of Community Psychology, 22, 399-414.

[12] Chalk, R \& King, PA 1998. Violence in families: assessing prevention and treatment programs, National Academy Press, Washington.

[13] Kraizer, S.K. 1986. Rethinking Prevention. Child Abuse \& Neglect, 10, 259-261.

[14] Battle, J. 1981. Manual for the Culture-Free Self-Esteem Inventory for Children Special Child Publications. 